\title{
Poetry and Pleasure
}

\author{
JACKSON MAC LOW
}

for Anne Tardos

It often seems to me that the whole point of art is pleasure-the pleasure of making artworks and the pleasure of experiencing them.

"Whole point" is both an overstatement and ambiguous. I wished to bring back to attention the fact that people make artworks both because doing so is pleasurable and in order to cause pleasure to others. There are also other notable reasons for doing so. The primary reason for making an artwork is to bring it into being. All others-even pleasure-are subsidiary to that.

There are many kinds of art-probably more kinds today than ever before. This may be because many more kinds of pleasure are admissible and admitted today than formerly. Some artists and art-experiencers gain simple pleasures from simple artworks. Others experience complex pleasures from complex artworks. But then, some obtain complex pleasures from simple artworks or simple pleasures from complex artworks. People are widely various. It follows that artworks are also. This variety is in itself one of the positive pleasure-giving aspects of living in a society where many kinds of people and many kinds of pleasure and many kinds of artworks are admissible and admitted.

It is probably a paradox that this can happen in a society in which many people and actions of people cause many kinds of pain-often kinds of pain that do not come about necessarily, as from diseases and injuries that cannot be avoided. The kinds of pain that people suffer in present-day societies are often due to clumsy social, economic, and political arrangements that simply need not be so clumsy, so slovenly. Some of them are the result of-and help to further the ends of-overweening impulses and desires. Many others are due to the infrastructures that bulwark present- 
day political, economic, social, and psychological systems. Now, the most glaring of all of these are the current wars and their results. So now more than ever there is a pressing prevailing need to change these arrangements and to prevent warfare and other causes of unnecessary suffering.

So many artists and experiencers of art believe that the point of art is to change these slovenly, pain-causing-and boredom-causing-arrangements. I do not think this "point" is at odds with pleasure. Artworks that cause pleasure can also-just because they give pleasure and because of the kinds of pleasure they give-cause shifts in social and economic arrangements, sometimes subtle shifts that may be partially caused by changes in the ways the materials of the arts are used and shaped. However, this is seldom something that can be aimed at directly. It is of course untrue that artworks "make nothing happen." But what they may make happen is never really predictable. This is why most agitprop artworks are such dismal failures, both as art and as social sanitation.

I refer, of course, to W. H. Auden's saying, in the second part of his poem "In Memory of W. B. Yeats" (February 1939) that "poetry makes nothing happen: it survives/In the valley of its making where executives/Would never want to tamper; . . . . . . it survives, / A way of happening, a mouth." This followed a period in the early 1930s when Auden, like a myriad of other idealistic people, was a "communist sympathizer" with no knowledge of the millions killed in the Soviet Union during the forced collectivization and murder of well-to-do peasants (1929-33) or of the Great Terror begun with the murder of Sergei Kirov, and the ensuing Moscow Trials (1936-38). (He was certainly no "Stalinist.") When he went to Spain, for seven weeks in early 1937 to become an ambulance driver for the Loyalists, but was put briefly to writing propaganda instead, he was shocked to find the churches in Barcelona closed. Though he had rejected the church, he found that the existence of churches and what happened in them were important to him. He supported the Loyalist government because he realized that if fascism spread worldwide, it would make life and work impossible for most artists and for everyone who cared for justice, liberty, and culture, but his poem "Spain" (April 1937) is much less committed than it seemed when he wrote it. By the end of that year he seems largely to have rejected political solutions to the current political, economic, and social horrors of which he was all too strongly aware. 
However, artworks do make things happen, at the very least, pleasure and pain. And the kinds of pleasures and pains they may cause are hardly ever predictable. (Thus Horace's never-followed admonition against arguing about tastes has more than a little justification.) The politically aware artist can hope that what gives her pleasure and what gives her pain will give others the kinds of pleasures and pains that may help engender more positive social arrangements. The point is still ultimately pleasure.

The classic example is tragedy, which first causes pain by arousing pity and terror and then, by ridding one of those feelings, leads to kinds of pleasure that would not have been experienced otherwise. (Also, some works may first cause boredom but ultimately, for those who "stick with them," pleasure.)

Verbal art, of which poetry is considered the prime exemplar (why, I don't know), is often thought to have a worthier end than "mere pleasure." Both that and pleasure itself are thought to be caused by either the matter or the form of the work. In the latter case the writer may be castigated as "formalist." The "form" of the work is thought to be the "point" of it and nothing more. Traditionally, this castigation has pointed toward a lack in the work's "content." It may be damned as trivial or somehow wrong or absent, for instance.

What seems strange is that a poet is seldom condemned as "materialist." Seldom is she jumped on because she takes too much care with, or delights too much in, her words themselves — the materials of her art-or the way they relate with each other. But perhaps this does not happen all that seldom! Think of Emily Dickinson, Gertrude Stein, and James Joyce. Their "materialist" works have been endlessly condemned-usually for qualities extraneous to the nature of their materials (except possibly in the case of Joyce, whose very materials - his words and/or the situations they bring to mind-have often been condemned as pornographic or scatological). Often a concentration on the materials of artworks rather than on their "content" has itself been considered "formalist."

The kinds of pleasure that poems may bring about are as various as the kinds of pleasure that poets may take in making them. (This is of course true also of the kinds of pain they may cause.) The reason why some poets delight in making poems in other ways - otherwise - than others do could be that they feel a need for other pleasures than those they've experienced 
from poems hitherto. This doesn't at all mean that they need reject the poems of others - past writers or those writing presently but not "otherwise"or the pleasures those poems may cause. (Unfortunately, many who write in more usual ways feel that "otherwise" works are attacks upon them and their own works. Those who strongly favor the coexistence of both usual and "otherwise" works get it from both sides.) It isn't even that some people "just delight in novelty." Some writers (and other artists) often delight in being surprised by what they make.

For more years than I care to remember I've often made verbal and other artworks by methods that insure that I will not always be in control of what comes into the works. (So what comes in may justly be said to be, to some significant degree, "unpredictable.") One group among many methods of this kind is what John Cage called "chance operations," which he first utilized in making music in the early ' 50 s and began in the late ' 60 s to use in making verbal works. Because of the fact that chance is associated with dice, works made by chance operations are often called "aleatory." This term may be appropriate for some kinds of chance-operational methods, such as the ones I devised and used most often between winter 1954 and spring 1960. However, it is quite inappropriate for other methods that also lead to unpredictable results that may surprise the artists as much as other experiencers.

A number of such methods that I've used since 1960 may justly be called "deterministic": what happens when they are utilized is not a matter of chance if one uses them without making mistakes. (I sometimes made some mistakes of this kind before my methods were automated as computer programs - and sometimes I still do so when I use unautomated methodsso chance may creep in willy-nilly.)

Two groups of deterministic methods that I've often utilized make use of two texts - a source text and a seed text. (Either text may have been written by the writer herself or by others.) Unlike chance operations, their outputs, when they're used correctly with the same source and seed texts, will always be the same. In one group the writer reads through a source text and finds successively words, phrases, sentence fragments, sentences, and/or other linguistic units that have the letters of the seed text as their initial letters. This group is called "acrostic reading-through text-selection methods." I devised and used some of these methods most often, but not exclusively, from May 1960 to January 1963, and occasionally since then. 
The other group of deterministic methods that make use of both source and seed texts are called "diastic reading-through text-selection methods." I first devised and utilized some of these methods in 1963. In using them, the writer (or her digitized surrogate) reads through the source text and successively finds words or other linguistic units that have the letters of the seed text in positions that correspond to those they occupy in the seed text. (The neologism "diastic" was coined on analogy with "acrostic" from the Greek words dia, through, and stichos, line. The writer "spells through" the seed text when she "spells it out" in linguistic units successively drawn from the source text which have the letters of the seed text in corresponding positions.)

Another group of deterministic methods, which I began using while writing my first chance-operationally composed works, "5 biblical poems," at the end of 1954 and the beginning of 1955, are ones in using which the writer "translates" the notes, rests, and/or other features of the notation of a musical work "into" words from some source text by either the writer or others. (As a composer I've sometimes used the opposite method of "translating" the letters and spaces of a verbal text into musical notation.)

Often all such methods - chance operations, deterministic methods, and others - are spilled into an indiscriminate bin labeled "Methods." (I avoid this term because it is all too redolent of surgery.) And all of them-along with quite different kinds of works — are often dubbed "aleatory" or "aleatoric." (This is especially true in music, where works that involve various degrees and kinds of choice on the part of performers-including many kinds of improvisation-are nevertheless called "aleatoric" because the composer herself has not made all the choices!) Everything in the bin may be tainted with a contempt or dislike that may arise from the fact that the artwork is thought not to be entirely the work of the individual artist. Whatever may come into it may not be the result of choices — on whatever levelof the artist. The dislike may arise from a kind of despair or fear that the "self"- the "subject"-is being intrinsically denigrated.

Indeed, these methods and others first arose from an attempt to lessen (or even vainly to try to do away with) the hegemony of the ego of the artist in the making of the artwork. This attempt first sprang from Buddhist considerations. Ultimately, the ego in the largest sense (in Zen and other Buddhist psychologies the ego includes all of the parts of the individual psyche, including all three of the Freudian "institutions" of the psyche, the 
ego, the id, and the superego-and in fact, the entire individual self) is considered to be a kind of temporary illusion consisting of five continually changing "baskets" of sensations, impulses, perceptions, emotions, and thoughts - to simplify the matter grossly. They stand in the way of a perception of reality that is somehow selfless.

What happened to me in the course of using such methods for several decades was that I realized that these methods, too, and the actions of utilizing them, are products of the ego, that the ego is inescapable except possibly when one reaches a clear and egoless state of open perception of reality. It was always obvious that I had not reached such a state, and it seems all too probable that I'll never reach it. Nevertheless, I came to find these methods, and the works made with their help, valuable in themselves. Things happen while using the methods — valuable things - that probably could not have come about without them.

In making "simultaneities"- poems and other verbal, verbal-musical, and musical works (as well as some involving actions and/or visual components) for groups of two or more persons in which the performers make choices among the verbal materials and/or nonverbal sounds that are given as "parts of the pieces"-I came, I still think rightly, to believe that I was making works that have a directly political value. The community made up of the performers is a model of a society that has certain characteristics that I would like to see abound in the wider society: the individual performers exercise initiative and choice at all points during the piece but are also-by listening intensely and responding to all they hear, both other performers' and ambient sounds both within and outside of the performance spaceconstructing an aural situation that is not merely a mixture of results of egoic impulses, but an aural construction that has a being of its own.

Ultimately, artmaking, including the making of poems, seems to me to be primarily the making of "objects" that are valuable in themselves. One can supplement this "in themselves" in many directions with various "becauses." The most obvious one is what I started with: pleasure. Artworks are valuable both in themselves and because they cause pleasure-kinds of pleasure not usually available from other sources. And "otherwise" artworks are valuable because they bring about new kinds of pleasure.

Social "becauses" abound: new kinds of poems, for instance, may change the ways people use and perceive language. The late Paul Connolly, fol- 
lowing Richard Rorty, said (as quoted in the flyer for the conference on poetry and pedagogy at Bard College in 1999) that speaking differently changes a culture and that different ways of speaking are most prevalent in poetry. This may well be true, but what guarantees that speaking differently will change our culture in ways we would find desirable?

Because I now find all writingways (and other artmakingways) valuable, I've pursued two main ways of writing during the 1990s and early 2000 s. Both of them are deeply involved with contingency, but differently than my writings were before 1990 .

From October 1990 to early 1995 I wrote the first drafts of the poem series 154 Forties, and before and since 1995 I've been revising them. I made the Forties by "gathering" words, phrases, etc., from my outer and inner environments, i.e., from whatever I happened to be hearing, seeing, or thinking of while writing their first drafts, and revising them afterwards. Each poem comprises eight five-line stanzas which have the "fuzzy verse form" of three moderately long lines followed by one very long line, and then a short line.

Although I revised the Forties' words in several ways, what I changed most were "caesural silences" and neologistic compounds. The former are notated as spaces of several different lengths within verse lines, which signify different durations of silence. Each of the latter link together two or more words and they are of two kinds, "normal" and "slowed-down" compounds, the former being read somewhat more rapidly than single words, the latter a little more slowly.

However, because I continue to find pleasure in being surprised by what I write, I've currently been pursuing a writingway involving both diastic reading-through text-selection, drawing sequences of single words from a source text, and careful revision of the output of this deterministic method. Prof. Charles O. Hartman of Connecticut College, New London, wrote the program DIASTEXT, a digitization of a form of diastic text selection that uses the whole source text as the seed text (a method that I had devised and discarded in 1963), and sent it to me in June 1989. Later, Prof. Hartman sent me several versions of his program that allow the use of separate source and seed texts.

With the help of DIASTEX5 (1994), I wrote Stein, a series of 161 poems, from April 1998 to the end of 2000 (frequently making revisions after that). 
Since 2000 I've been I've been pursuing this writingway while using other sources, such as poems by Keats, Gerard Manley Hopkins, and Rosmarie and Keith Waldrop and prose by the philosopher Charles Hartshorne.

Recently I've realized that Charles Hartman, by sending me these programs, "gave me permission" (as Robert Duncan would have said) to combine a "deterministic" method of text selection, whose source and/or seed texts might be determined by "nonintentional" methods and whose output is unpredictable, with the free composition of poems, within specific constraints. This happened because reading through the source text to find the output words - the most labor-intensive part of reading-through text selectionhad been automated and become almost instantaneous. Since I'd come to realize that so-called nonintentional methods of composition were no more Buddhist than other ways of making artworks (because they too are egoic), there was no reason not to combine all my writingways as I usually do now.

In writing Stein, I sometimes utilized random-digit chance operations, numerological operations, or other means to locate the page numbers of source texts and seed texts by Gertrude Stein in A Stein Reader, ed. Ulla E. Dydo (Evanston, IL: Northwestern University Press, 1993), a collection in making which the editor had recourse to the texts' earliest manuscripts and typescripts. In making later poems in Stein, I sometimes used such methods to locate "seed texts" in Stein's Tender Buttons to use with the whole book as source text. I usually revised the output of this automated "deterministic" method, but occasionally I chose to accept the minimally revised "raw output" of the program as a poem. I haven't yet done so when making poems by diastic text selection and revisionary composition of this output from other sources and seeds by other authors than Gertrude Stein.

To articulate the poems in strophes, I've often made use of a number sequence derived from an algebraic sequence that the French mathematician Edouard Lucas devised to test for Mersenne prime numbers and published in $1880 .{ }^{1}$ This sequence-1, 3, 4, 7, 11, 18, 29, etc.-determines the numbers of verse lines (which are often normative sentences) or of typographical lines, in successive strophes of the poems. I've sometimes em-

1. A Mersenne prime is a specific type of prime number, named after its inventor, the French monk Marin Mersenne (1588-1648), which must be reducible to the form $2^{n}-1$, where $n$ is a prime number. The 44 th Mersenne prime, $2^{32,582,657-1}$, was found on September 11, 2006.-A.T. 
ployed an extension of this sequence that ascends, then descends, then ascends, etc. (e.g., 1, 3, 4, 7, 11, 18, 29, 18, 11, 7, 4, 3, 1, 3, 4, 7, 11, 18, 29, $18,11,7$, etc.). Alternately, I've sometimes used the sequence of whole numbers $(1,2,3,4$, etc.) or that of prime numbers $(2,3,5,7$, etc.), and sometimes I've found a plausible sequence of numbers of lines, etc., in the paragraphs of an unrevised output.

In short, I make poems such as those in Stein by using the outputs of a digitized method as raw materials for free composition within specific constraints. The most important constraint is to use the root morphemes of all the nouns, verbs, adjectives, and adverbs in the output to make the lines of the poems. "Helping words"-structure words such as prepositions and conjunctions, but also pronouns and forms of "to be," "to do," and "to make"are freely modified, deleted, or added to. Although in many of these poems the lines are complete normative sentences, in others they're not. Often these verse lines are such that the reader or hearer must exercise initiative and imagination to find or make these sentence sequences meaningful. When I modify the output minimally, so that all or most of the words retain the forms that the author of the source text (e.g., Stein) gave them, the reader or hearer has to "mine" the individual "sentences" for meanings.

Often the poems I make in these ways surprise me in different ways. How I modify the result of an initial method is often a function of my reaction to it, which I can hardly ever predict. Most of my recent ways of workingwhich during the 1990s, until I began the Stein series in 1998, hardly ever involved either chance operations or deterministic methods-have several things in common: they are almost always ways in which I engage with contingency.

At first I'm in charge, to whatever extent I allow, of what happens when I select the method and source and seed text. In the moment when these are "run through" the digitized method I'm not in charge at all, but from then on I am free to compose the poems (utilizing the root morphemes of lexical words and other words as described above). I am as free to make use of my imagination and acoustic, semantic, and other skills as any poet who commits herself to work within limits such as those imposed by a verse form. Though I "engage with contingency," in doing so, I've determined in each case the boundaries of that contingency. The kinds of poetry made in these ways are hardly "found poetry." 
Writing in ways that combine method, contingency, and free composition and the poetry and other work produced by doing so not only surprise me. They often give me pleasure. And I'm glad to say that people I can believe have said that the results of these writingways have also given them pleasure.

New York: March, June 1999; March-April 2002 